\title{
Nurses' Role in Birth Preparedness and Complication Readiness among Pregnant Women in University of Calabar Teaching Hospital, Calabar
}

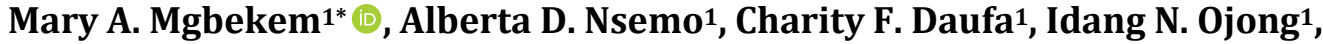 \\ Ndukaku Nwakwue1, Priscila Andrew-Bassey² \\ ${ }^{1}$ Department of Nursing Science, University of Calabar, Calabar, Nigeria \\ ${ }^{2}$ University of Calabar Teaching Hospital, Calabar, Nigeria \\ Email: *achimgbekem@yahoo.com
}

How to cite this paper: Mgbekem, M.A., Nsemo, A.D., Daufa, C.F., Ojong, I.N., Nwakwue, N. and Andrew-Bassey, P. (2020) Nurses' Role in Birth Preparedness and Complication Readiness among Pregnant Women in University of Calabar Teaching Hospital, Calabar. Health, 12, 71-85.

https://doi.org/10.4236/health.2020.122006

Received: September 26, 2019

Accepted: January 18, 2020

Published: January 21, 2020

Copyright $\odot 2020$ by author(s) and Scientific Research Publishing Inc. This work is licensed under the Creative Commons Attribution International License (CC BY 4.0).

http://creativecommons.org/licenses/by/4.0/

\section{Open Access}

\begin{abstract}
Background: Birth preparedness and complication readiness (BPCR) promotes timely information and utilization of skilled health attendance/services to pregnant women to prevent complications due to 3 delays that lead to maternal deaths. Objective: To determine nurses' role in birth preparedness and complication readiness among pregnant women in University of Calabar Teaching Hospital Calabar. Methods: This study adopted a survey research design. Simple random sampling technique was used to select a sample size of 80 participants working in antenatal clinic, antenatal ward, gynecological ward, labour ward, postnatal ward, and Family planning unit. Data were collected using self-administered structured questionnaires. Data were analyzed using frequency, percentage and Pearson Moment Product Correlation Coefficient statistical methods of data analysis. Results: Findings of the study revealed that $53(66.3 \%)$ of the respondents acknowledged nurse/midwives responsibility for the health education of mothers on dangers of pregnancy while 42 (52.5\%) strongly agreed that nurses/midwives carry out discussion on plan for delivery with mothers. The study hypothesized that there is no significant relationship between the role of nurse/midwives and the practice of BPCR among pregnant women. The correlational analysis result that there is no revealed $(\mathrm{r}$-cal $=0.67, \mathrm{r}$-crit $=0.58, \mathrm{df}=79, \mathrm{P}>0.05)$ thus rejecting the hypothesis statement as $r$-calculated was greater than $r$-critical. This implies that the role of nurse/midwives have very strong positive relationship with the practice of BPCR among pregnant women. Conclusion: Positive pregnancy outcome depends on nurse/midwives independent and interdependent roles to prevent delays, emergencies, have access to skilled care.
\end{abstract}




\section{Keywords}

Nurses' Role, Birth, Preparedness, Complication Readiness Pregnant Women

\section{Background to the Study}

High maternal mortality is a serious public health challenge especially in developing countries. Most maternal deaths are avoidable, yet occur during labour, delivery and within 24 hours postpartum. The World Health Organization (WHO) [1], reports estimated maternal mortality ratio (MMR) in developing countries at 239 per 100,000 live births and 12 per 100,000 live births in developed countries. The Nigerian Demographic and Health Survey (NDHS) report for Nigeria in 2013 [2] shows that Nigeria has a maternal mortality ratio (MMR) of 545 deaths/100,000 live births; estimated to be $13 \%$ of the global maternal deaths [3] with an increase MMR in 2015 with an estimated 814 per 100,000 live births [4]. This unhealthy ranking resulted in the emphasized on the Integrated Maternal Newborn and Child Health (IMNCH) strategy by Nigeria's federal ministry of health to revitalize primary health care key maternal and child health interventions. Despite government efforts in the aforementioned, maternal mortality is still a common problem in Nigeria. Most maternal deaths are preventable as they are related to direct obstetrical complications such as hemorrhage, post-partum infection, obstructed labour and hypertensive disorders-all of which are treatable. Apart from medical causes, there are numerous interrelated socio-cultural factors which delay care seeking and contribute to maternal death. Maternal morbidity and mortality could be prevented if women and families recognize obstetric danger signs and promptly seek health care. Thus the need to mobilize when danger signs are recognized is apparent.

Birth preparedness and complication readiness (BPCR) is one of the components of focused Antenatal care (FANC) and is a key strategy in safe motherhood programme whose aim is to reduce delays in seeking, reaching and receiving care [5]. BPCR promotes timely utilization of skilled maternal and neonatal care [6] [7] [8]. It is care that addresses the pregnant woman, family, community, health facility, health service provider, and policy makers, to plan births and effectively deal with emergency complication by utilizing the existing health care delivery system to reduce maternal mortality ratio (MMR); a quality indicator of obstetric care. MMR is defined as maternal deaths per 100,000 live births over a given period. It varies from approximately 10 in developed countries to 1000 in least developed countries [9]. Maternal mortality according to Acharya, Kaur, Prasuna, \& Rasheed [10] is the most significant outcome of poor maternal health. Many women in developing countries experience life-threatening and other serious health issues related to pregnancy and childbirth. Among the issues is inadequate or lack of birth and emergency preparedness, a key component of globally acceptable safe motherhood programs [11] [12]. Birth preparedness and 
complication readiness (BPCR) according to Miltenburg, Roggeveen, Shields et al. [13], is a process of planning for birth and anticipating action to take in case of obstetric complications. Wurapa, Abidey, Ankomah and Ayaga [14], opined that the role of nurse/midwives in BPCR is to improve the use and effectiveness of key maternal and neonatal services through reducing delays in deciding to seek care. It motivates people to plan to have a skilled provider at every birth. Decisions are made and documented on choice of birth, the preferred skilled birth attendant, items required for birth, birth comparisons, getting a compatible blood donor if necessary and arranging in advance for transport. Barimani, \& Hylander [15] posit that BPCR promotes preventive behaviours, improves knowledge of mothers about danger-signs and leads to improved health-seeking behaviour during obstetric emergency. The concept of birth preparedness thus, encourages the planning for normal pregnancies, deliveries, and postnatal periods and to prepare to deal effectively with emergencies if they occur to overcome delays (in seeking, reaching and receiving health care) leading to most maternal deaths. At the basic level, the concept of BPCR includes identifying a trained medical facility capable of providing emergency services, arranging for transport for delivery or obstetric emergency, saving money for delivery and identifying a compatible blood donor. All these factors are categorized under the following: institutional, Community, Socio-demographic and Maternal [16] [17] [18] [19]. Odetola [20], asserts that access to information about maternal services with emphasis on the factors relating to BPCR in the community will help women make choices about who to see, where to go, and type of care they require.

Women understanding and preparation in handling unforeseen events that may arise during pregnancy and delivery are determine by nurse/midwives knowledge of BPCR. Abiyot, Kassa, Buruh and kidanu [21], Ekabua [22] report that about $80 \%$ of maternal deaths especially in developing countries are as a result of obstetric complication such as haemorrhage, infection, obstructed labour, unsafe abortion and high blood pressure, factors known as danger signs associated with maternal death that can be prevented with appropriate information given during ANC. Morhason-Bello, Fagbamigbe, Mumilni, Adesina et al. [23], state that early recognition of danger signs is an important indicator to seek care from healthcare facilities with skilled birth attendant promptly. These danger signs can only be discussed with the pregnant women at ANC if the caregivers have knowledge of them. The danger signs can occur in any of the three stages below:

* Pregnancy: vaginal bleeding, headache, fever, drainage of liquor, abdominal pain, blurring vision, facial and hand swelling.

* Labour and childbirth: Severe vaginal bleeding, prolonged labor (>12hours), convulsions, retained placenta.

* Postpartum period: Severe vaginal bleeding, foul-smelling vaginal discharge, high fever.

* Signs in the newborn: Convulsions/spasms/rigidity, difficult/fast breathing, very small baby, lethargy/unconsciousness. These danger signs demand im- 
mediate attention to save both mother and child.

Avoidable delays are said to be in phases [24] [25], These are:

- Phase I-delay in deciding to seek care by individual and /or family.

- Phase II-delay in reaching an adequate health care facility.

- Phase III-delay in receiving adequate care at the health facility.

Phase I delay-delay in deciding to seek care

This delay is associated with mothers and or family's decisions to seek care. When proper and adequate informed about the nature o are provided at ANC, the first delay can be prevented.

\section{Phase II delay-delay in reaching an adequate health care facility}

This occurs due to bad road conditions, lack of transportation and unavailability or access to vehicles thereby resulting in long waiting time (Hours or days) to reach a care facility. Women with life-threatening conditions often may not make it to the facility in time [5].

Phase III delay-Inadequacies within the health care system

Pacagnella et al. [26] say inadequacies within the health care system (lack of skilled personnel or infrastructural inadequacies, late or wrong diagnosis, incorrect action by the staff and untimely provision of needed care) has be found to harm to women. Nurse/midwives' knowledge of these delays and collaboration is key to BPCR [27] [28] [29].

Nurses and midwives are the largest workforce in the healthcare system, inadequate care by this workforce will not only affect the patient, it adversely affects the entire society they care for. It is also observed that nurse/midwives attitudes are often influenced by culture, religion, personal experience and professional background. These factors in turn influence care. However, the nurse/ midwife-relationship should be such that ensures that the birth experience is fulfilling and gratifying. This type of relationship will improve uptake of ANC attendance and reduce poor utilization of quality health services that contribute to maternal mortality rate [28]. The antenatal care visits offer the nurse opportunity to partner with pregnant women, their family and communities to tackle, in a timely manner, obstetric complications that lead to death. The role of the nurse in BPCR is thus critical in providing the best possible reproductive health care information and education during these visits before clinical consultations to raise awareness on expectations of pregnancy and it outcomes including danger signs of pregnancy. The expectation is that the information could act as a catalyst to seek care and possibly avert serious adverse pregnancy outcomes and fatalities. Educating pregnant women during antenatal visits thus bring significant improvement in their birth preparedness practices enabling them make informed choices about pregnancy and birth [29]. To explain the importance of information needed, the perspective of Newman's Health as Expanding Consciousness was adopted to increase nurses' understanding as caregivers and promote intervention strategies that impact the care giving experience. This study therefore aimed at determining the role of nurses in BPCR among pregnant women attending antenatal care in University of Calabar Teaching Hos- 
pital, Calabar hypothesized that there is no significant relationship between the role of nurses and the practice of BPCR among pregnant women in UCTH Calabar.

\section{Theoretical Framework}

The theory of Health as Expanding Consciousness (HEC) by Margaret Newman [30] was adopted for this study. Margaret Newman's theory of health as expanding consciousness describes a process of becoming more of oneself; finding greater meaning in life and reaching new dimensions of connectedness with other people and the world [31]. HEC supports the Nurse-patient relationship experience through caring partnership. Through dialogue and the intentional presence of the nurse, patient pattern appraisal occurs, meaning is uncovered, and new insights are gained that promote opportunities for choices and change. When actions are initiated to foster change, there is movement and growth, increased awareness for the nurse and patient, and discovery and personal transformation. HEC promotes the integration of nursing knowledge across theory, research, and practice that fosters the evolving of new knowledge by nurses to improve the lives of people globally.

\section{Application of HEC to the Study}

The HEC is a theory that assists people to recognize the power that is within them to move to higher levels of consciousness. The theory synthesizes the assumptions as shown below to the study.

Health

Pregnancy is not an illness or disease; it should be seen as a state of wellness. Margaret Newman's theory of health as expanding consciousness states an individual is a unified whole in constant interaction with the environment. In the context of this study, it recognizes that preparation for childbirth is holistic and goes beyond the physiological readiness of the mother, to encompass psychological, intellectual, social and financial preparedness. The nurse holistically evaluates the client's readiness for delivery and facilitates behavior that promotes health, wellness and self-care through health education. Based on this theory, preparing for childbirth and being ready for complication reduces delays in obtaining care and thereby impacting positively on birth outcomes [33] [34].

\section{Pattern}

Pattern recognition and health professional awareness of the pattern of others through therapeutic relationship brings about improved interventions. According to Owino, Legault, Mumbo, Odera \& Ayugi [35] the success of the ante-natal process to a safe delivery, is a meaningful nurse-client interaction for childbirth. BPCR program is effective in raising women's obstetric knowledge, which is significantly associated with physical, emotional, psychological preparation and facility delivery. The willingness of an ante natal mother to attend ANC clinic early and regularly opens the way for dialogue, enabling exchange of information 
between nurse and client on key danger signs indicators in pregnancy, financial readiness for eventualities, timely referral for essential obstetric care and preparation for baby's arrival. Through dialogue, women discover choice points; achieve insight and progress through turning points to transformations (saving money, identifying an emergency care facility, planning a means of transportation) and involvement of the community for care a/assistance [36]. Owino, [37] [38] asserts that a woman not emotionally ready, finds difficulty in coping with pregnancy changes resulting in anxiety and fear during pregnancy. As the nurse dialogues and shares impressions and feelings with the pregnant women, pattern recognition occurs (a burst of insight when everything fits together and the client can see clearly and understand better), which then opens the way for transformation. Through pattern recognition, planning for birth is stronger; clients and their families are more likely to be ready for birth and its complications.

\section{Expanding consciousness}

Pattern recognition brings about heightened understanding, and the pathways for action. Nurses thus must assess and reassess clients throughout the antenatal process to the exit phase to ensure a woman's readiness for birthing. It ensures pregnant women responses to determine effectiveness of information for BPCR, or checks the need to rearrange priorities to meet the changing demands of care. It enables the nurse address the clients' agendas, attending to what is important to them, and the choices likely to take place. This action assist both the pregnant woman and the nurse reach a higher level of consciousness together. Relationships that are more open, caring, loving, connected and peaceful are usually manifestation of expanding consciousness.

\section{Methods}

A, survey research design was adopted for this study. A stratified random sampling technique was used to select 80 participants from a target population of 100.midwives/nurses working in the following units: Antenatal clinic, Antenatal ward, Gynecological ward, ward, Labour ward, Post-natal ward, and Family planning unit) in University of Calabar Teaching Hospital (UCTH). The selection was based on the proportion of the subgroups in each unit. A self-administered structured questionnaire using likert type structured questions was used for data collection. The questionnaire was constructed along the lines of the objectives (content validity) and given to experts in obstetrics and gynecology for further assessment and suggestions to improve the items on the instrument.

The instrument reliability was ensured by a test retest administration of the instrument to ten (10) nurses from General Hospital Calabar and re-administration after one week, to assess its consistency. Test retest data were analyzed using Pearson moment correlation coefficient statistics with a result of 0.7 Cronbach. Ethical approval was obtained from the University of Calabar Research Ethics Committee. Written consent was also obtained from participants after explain- 
ing the aim of the study to the potential study participants. Participants were assured of confidentiality of their information and were informed that they had the right to withdraw from the exercise if they so wish at any time of the study. Data was collected through face-to-face administration of questionnaire from participants working in antenatal clinic, antenatal, labour, gynaecological, post-natal wards and family planning clinic. The data collected was analyzed using inferential and non-inferential statistical methods of data analysis.

\section{Results}

The demographic data in Table 1 showed that out of the 80 respondents, 49 (61.3\%) were between 30 - 39 years, 23 (28.7\%) between ages of 18 - 29 years and $8(10.0 \%)$ were 40 years and above. All respondents were ranked based on their professional qualification as: NO I, NO II, SNOs, PNOs and ACNOs. Participants with higher educational qualification of BNSc/BSc and MSc were very few as shown on the table. Findings on working experience revealed that majority (40.0\%) of the respondents had between 6 - 10 years working experience, $11.3 \%$ between 16 - 20 years while $3.7 \%$ had between 21 - 25 years accordingly. Others groups working experience is as shown on the table. The table also shows the percentage of participants based on their working units Viz: 13 (16.3\%) antenatal clinic, 16 (20\%) gynecological ward, 6 (7.5\%) Family planning clinic, 16 (20\%) ante-natal ward, 15 (18.7\%) post-natal ward and 14 (17.5\%) Labour ward.

Research question: What are the roles of nurse/midwives in birth preparedness and complication readiness in UCTH, Calabar?

Results in Table 2 shows 53 (66.3\%) of the respondents said nurses/midwives are responsible for the health education of pregnant women; 42 (52.5\%) strongly agreed that nurses/midwives carry out discussion on plan for delivery with mothers; $51(63.7 \%)$ stated that nurses/midwives collaborate with other health professionals during birth related emergencies; 54 (67.5\%) strongly agreed that nurses/midwives provide information on family planning services and teaching on baby care skills in the postnatal period; 31 (38.7\%) agreed that nurses/midwives coordinate the process of BPCR and 35 (43.7\%) strongly agreed that nurses/midwives should advocate for good road and other facilities with community leaders.

Hypothesis testing: There is no significant relationship between the role of nurses and the practice of BPCR among pregnant women in UCTH, Calabar.

Calculated value $=0.6717$, Critical value $=0.5824 \mathrm{df}=79,0.05$ level of significance.

Decision rule: If $\mathrm{r}$ cal $>\mathrm{r}$ crit, reject $H_{0}$, Otherwise, accept $\mathrm{H}_{0}$.

Since the $r$-calculated value $(0.67)$ is greater than the $r$-critical value $(0.58)$, with a degree of freedom of 79 at 0.05 level of significance, the null hypothesis which stated that there is no significant relationship between the role of nurses and the practice of BPCR among pregnant women in UCTH, Calabar is rejected. This implies that the role of nurses has a very strong positive relationship with the practice of BPCR among pregnant women in UCTH, Calabar. 
Table 1. Socio-demographic data of respondents $(n=80)$.

\begin{tabular}{|c|c|c|}
\hline Variable & Frequency & Percentage \\
\hline \multicolumn{3}{|l|}{ Age } \\
\hline $18-29$ years & 23 & 28.7 \\
\hline $30-39$ years & 49 & 61.3 \\
\hline 40 years and above & 8 & 10.0 \\
\hline Total & 80 & 100 \\
\hline \multicolumn{3}{|l|}{ Rank } \\
\hline ACNO & 5 & 6.3 \\
\hline PNO & 9 & 11.2 \\
\hline SNO & 12 & 15.0 \\
\hline NO I & 32 & 40.0 \\
\hline NO 11 & 22 & 27.5 \\
\hline Total & 80 & 100 \\
\hline \multicolumn{3}{|l|}{ Professional qualification } \\
\hline $\mathrm{RN} / \mathrm{RM}$ & 36 & 45.0 \\
\hline $\mathrm{RN} / \mathrm{RM} / \mathrm{RPN}$ & 19 & 23.7 \\
\hline B. N. Sc/BSc & 21 & 26.3 \\
\hline MSc/Others & 4 & 5.0 \\
\hline Total & 80 & 100 \\
\hline \multicolumn{3}{|c|}{ Years of working experience at UCTH } \\
\hline $1-5$ years & 20 & 25.0 \\
\hline $6-10$ years & 32 & 40.0 \\
\hline $11-15$ years & 15 & 18.7 \\
\hline $16-20$ years & 9 & 11.3 \\
\hline $21-25$ year & 3 & 3.7 \\
\hline 26 years and above & 1 & 1.3 \\
\hline Total & 80 & 100 \\
\hline \multicolumn{3}{|l|}{ Area of practice } \\
\hline Ante-natal clinic & 13 & 16.3 \\
\hline Gynaecological ward & 16 & 20 \\
\hline Family planning clinic & 6 & 7.5 \\
\hline Ante-natal ward & 16 & 20 \\
\hline Post-natal ward & 15 & 18.7 \\
\hline Labour ward & 14 & 17.5 \\
\hline Total & 80 & 100 \\
\hline \multicolumn{3}{|c|}{ Practice of birth preparedness and complication readiness } \\
\hline Yes & 80 & 100 \\
\hline Total & 80 & 100 \\
\hline
\end{tabular}


Table 2. Roles of nurses/midwives in birth preparedness and complication readiness in UCTH, Calabar $(\mathrm{n}=80)$.

\begin{tabular}{|c|c|c|c|c|c|c|c|c|c|c|}
\hline \multirow{3}{*}{ Variable } & \multicolumn{10}{|c|}{ Response } \\
\hline & \multicolumn{2}{|c|}{ SA } & \multicolumn{2}{|c|}{ A } & \multicolumn{2}{|c|}{$\mathrm{D}$} & \multicolumn{2}{|c|}{ SD } & \multicolumn{2}{|c|}{ Total } \\
\hline & No. & $\%$ & No. & $\%$ & No. & $\%$ & No. & $\%$ & No. & $\%$. \\
\hline $\begin{array}{l}\text { Nurses are responsible for } \\
\text { Health education of mothers } \\
\text { on dangers of pregnancy }\end{array}$ & 14 & 17.5 & 53 & 66.3 & 7 & 8.7 & 6 & 7.5 & 80 & 100 \\
\hline $\begin{array}{l}\text { Discussion on plan for } \\
\text { delivery with mothers is } \\
\text { part of ANC services }\end{array}$ & 42 & 52.5 & 26 & 32.5 & 7 & 8.7 & 5 & 6.3 & 80 & 100 \\
\hline $\begin{array}{l}\text { Collaboration with other health } \\
\text { professionals during birth related } \\
\text { emergencies is essential to improve } \\
\text { health outcomes of pregnancy. }\end{array}$ & 51 & 63.7 & 14 & 17.5 & 9 & 11.3 & 6 & 7.5 & 80 & 100 \\
\hline $\begin{array}{l}\text { Providing information on family } \\
\text { planning services and teaching on baby } \\
\text { care skills in the postnatal period help } \\
\text { mothers make informed decisions. }\end{array}$ & 54 & 67.5 & 19 & 23.7 & 2 & 2.5 & 5 & 6.3 & 80 & 100 \\
\hline $\begin{array}{l}\text { Coordinating the process } \\
\text { of BPCR is sole responsibility } \\
\text { of nurses/midwives. }\end{array}$ & 26 & 32.5 & 31 & 38.7 & 14 & 17.5 & 9 & 11.3 & 80 & 100 \\
\hline $\begin{array}{l}\text { Nurses' ability to advocate for provision } \\
\text { of good roads and other facilities with } \\
\text { community leaders ease transportation } \\
\text { of women to health facilities }\end{array}$ & 35 & 43.7 & 28 & 35.0 & 8 & 10.0 & 9 & 11.3 & 80 & 100 \\
\hline
\end{tabular}

\section{Discussion of Findings}

Several studies have been conducted on BPCR among pregnant women [5] [10]; post-natal mothers [18] [22], fathers' participation [16] and skilled care use [23]. Conversely, there is no study on the role of nurses on BPCR. This study was therefore carried out to determine the role of nurses on BPCR. Findings from the study reveal that nurses/midwives are responsible for the health education of pregnant women. This finding agrees with da Gama et al. [39] functions of nurse/midwives' health education promotion role in public health and role in birth preparedness. Although majority of this study participants reported carrying out discussions on birth preparedness, most pregnant women do not have a clear plan of what to do for birth preparedness or in obstetric emergency. It thus showed that education and counselling that form the bedrock of birth preparedness is either not given at all or content not clearly explained during clinic visits. This observation could be attributed to the time the women present themselves for ANC services giving the nurse/midwives little or no time for appropriate and adequate health education as reported in many research studies [7] [10] [12] [13] [14] [35] [36]. The use of HEC (Figure 1) should assists nurses and women to recognize the power that is within them to move to higher levels of consciousness based on the health, pattern and expanding consciousness assumptions in a process of becoming more of oneself; finding greater meaning 


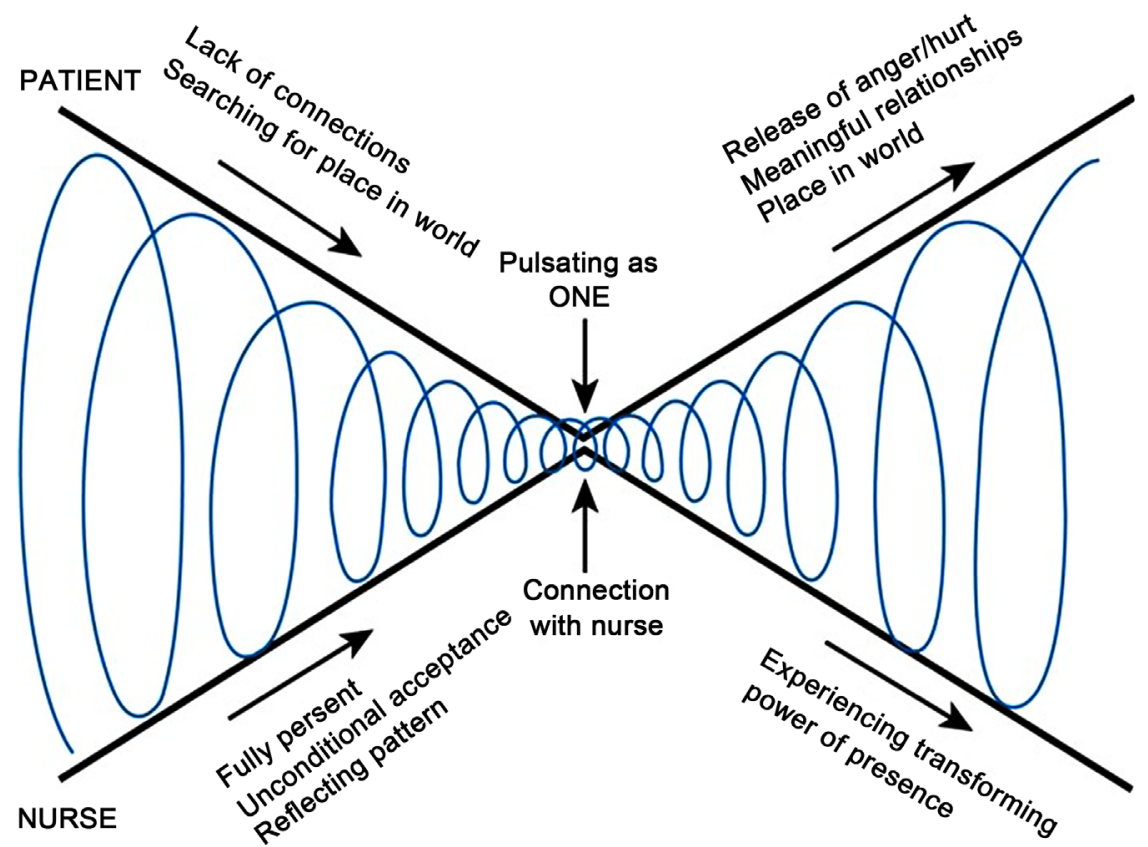

Figure 1. The theory of Health as Expanding Consciousness (HEC). Nurse and patient coming together and moving apart in process recognition, insight, and transformation. Adapted from Newman [32]. Transforming presence: The difference that nursing makes (p. 35). Philadelphia: F. A. Davis.

in life and reaching new dimensions of connectedness with other people and the world [31]. This assertion is noted in $63.7 \%$ response rate of the participants in Table 2 that collaboration is essential for achievement of BPCR. Nurse-patient relationship experience through caring partnership can easily be achieved with the use of this theory.

Birth preparedness, an independent role of the nurse/midwife during prenatal periods requires clear documentation in client ANC folder for easy identification of birthing plans and those to be contacted in emergencies. This approach helps to reduce the delays, safe life and birth experience satisfaction [37]). One of the roles of the midwives is collaboration with other health professionals [34]. The collaborative care approach by nurse/midwives was stated by the participant (63.7\%) response rate and supported by Aquino, Olander, Needle \& Bryar, [26] systematic review on midwives' and health visitors' collaborative relationships across care service continuum and da Gama and colleagues (2016) identification of potential benefit of collaborative work between physicians and nurses/midwives in labour and birth care. Midwives education of mothers continue to postnatal period on family planning and care of the baby. This study identified this independent role provided for women during postnatal period in agreement with Dol, et al. [34] on exploring maternal postnatal newborn care and postnatal discharge education and Bagheri et al. [14] five concepts for continuous midwifery-led care in an environment that meet women's individual needs and concerns [17]. In the community setting, the midwife is expected to play a leadership role of coordinating the care of the pregnant woman till delivery thus ensuring support 
Table 3. Pearson's analysis of the relationship between the role of nurses and the practice of birth preparedness and complication readiness among pregnant women in UCTH, Calabar $(\mathrm{n}=80)$.

\begin{tabular}{cccccc}
\hline VARIABLES & $\mathrm{N}$ & Mean & Standard deviation & $\mathbf{r}_{\text {cal }}$ & $\mathbf{r}_{\text {crit }}$ \\
\hline Role of nurses & 80 & 37.5 & 30.9 & & \\
Practice of BPCR & 80 & 29.1 & 22.8 & $\mathbf{0 . 6 7 1 9}$ & $\mathbf{0 . 5 8 2 4}$ \\
\hline
\end{tabular}

and continuity of care consistent with mothers' expectations [10] [15]. In this study as shown on Table 2, 38.7\% of the respondents agreed that this interdependent role is performed through coordination process to achieve BPCR. However, it is sad to note that some participants could not implement vision and strategies recommended by World Health Organization [1] [27] [28], for BPCR interventions that increase the timely use of healthcare facilities. Findings of this study revealed that 35 (43.7\%) (Table 2) of participants strongly agreed that nurses/midwives should play leadership role of advocating for good roads and health facilities with community leaders to prevent delays and safe women's lives as supported by Bagheri, et al. [14], Idemudia, \& Fagbamigbe [16], Freytsis et al. [35] advocacy role. This role will only be achieved when pregnant women register for care early and not present themselves late in the $3^{\text {rd }}$ trimester or in labour. Based on the study findings, hypothesis testing stating that there is no significant relationship between the role of nurses and the practice of BPCR was rejected as the $r$-calculated value $(0.67)$ was greater than the $r$-critical value $(0.58)$, with a degree of freedom of 79 at 0.05 level of significance showed a very strong positive relationship with the practice of BPCR as reported in Table 3.

\section{Limitations}

This study determined the roles of nurses in BPCR in a tertiary healthcare facility. The results of this research are not intended to be generalizable across time or with a more geographically diverse group of nurses. This is a study limitation, but the findings are an important reminder about the gaps in communication and role understanding that often exist between nurses and their clients.

\section{Conclusion}

The responsibility of the professional nurse/midwife is to establish a primary relationship with the client for the purpose of identifying meaningful patterns and facilitating the client's action potential and decision-making ability to achieve a successful management and outcome of pregnancy, labour and puerperium. The study concludes that positive pregnancy outcome depends on nurse/midwives roles in BPCR through health education of mothers on danger signs of pregnancy, plans for delivery, prevention of delays to seek skilled healthcare provider services, collaboration with other health professionals during birth related emergencies, provision of information on family planning services and teaching on baby care skills in the postnatal period. 


\section{Conflicts of Interest}

The authors declare that there is no conflict of interest.

\section{References}

[1] World Health Organization (2015) WHO Recommendations on Health Promotion Interventions for Maternal and Newborn Health 2015. World Health Organization, Geneva.

[2] National Population Commission-NPC/Nigeria and ICF International (2014) Nigeria Demographic and Health Survey 2013. NPC/Nigeria and ICF International, Abuja, Nigeria.

[3] Idowu, A., Deji, S.A., Aremu, A.O., Bojuwoye, O.M. and Ofakunrin, A.D. (2015) Birth Preparedness and Complication Readiness among Women Attending Antenatal Clinics in Ogbomosho, South-West, Nigeria. International Journal of Maternal and Child Health and AIDS, 4, 47-56. https://doi.org/10.21106/ijma.55

[4] The World Health Organization, United Nations Children's Fund, United Nations Fund for Population, The World Bank (2014) Trends in Maternal Mortality: 19992013. Estimates by WHO, UNICEF, UNFPA, The World Bank and the United Nations Population Division. Geneva.

https://openknowledge.worldbank.org/bitstream/handle/10986/18203/879050PUB0 Tren00Box385214B00PUBLIC0.pdf?sequence $=1$

[5] August, F., Pembe, A.B., Kayombo, E., Mbekenga, C., Axemo, P. and Darj, E. (2015) Birth Preparedness and Complication Readiness-A Qualitative Study among Community Members in rural Tanzania. Global Health Action, 8, 26922.

https://doi.org/10.3402/gha.v8.26922

[6] JHPIEGO (2001) Maternal and Neonatal Health (MNH) Program. Birth Preparedness and Complication Readiness: A Matrix of Shared Responsibilities. MNH.

[7] JHPIEGO (2004) Maternal and Neonatal Health. Monitoring Birth Preparedness and Complication Readiness Tools and Indicators for MNH. Johns Hopkins Bloomberg, School of Public Health Center for Communication Programs Family Care International, Baltimore. http://pdf.usaid.gov/pdf_docs/Pnada619.pdf

[8] Ibrahim, I.A., Owoeye, G.I.O. and Wagbatsoma, V. (2013) The Concept of Birth Preparedness in the Niger Delta of Nigeria. Greener Journal of Medical Sciences, 3, 1-7. https://doi.org/10.15580/GJMS.2013.1.011313380

[9] Sabageh, A.O., Adeoye, O.A., Adeomi, A.A., Sabageh, D. and Adejimi, A.A. (2017) Birth Preparedness and Complication Readiness among Pregnant Women in Osogbo Metropolis, Southwest Nigeria. Pan African Medical Journal, 27, 74. https://doi.org/10.11604/pamj.2017.27.74.7266

[10] Acharya, A.S., Kaur, R., Prasuna, J.G. and Rasheed, N. (2015) Making Pregnancy Safer-Birth Preparedness and Complication Readiness Study among Antenatal Women Attendees of a Primary Health Center, Delhi. Indian Journal of Community Medicine: Official Publication of Indian Association of Preventive \& Social Medicine, 40, 127-134. https://doi.org/10.4103/0970-0218.153881

[11] Hailu, M., Gebremariam, A., Alemseged, F. and Deribe, K. (2011) Birth Preparedness and Complication Readiness among Pregnant Women in Southern Ethiopia. PLoS ONE, 6, e21432. https://doi.org/10.1371/journal.pone.0021432

[12] Affipunguh, P.K. and Laar, A.S. (2016) Assessment of Knowledge and Practice towards Birth Preparedness and Complication Readiness among Women in Northern Ghana: A Cross-Sectional Study. International Journal of Scientific Reports, 2, 121 - 
129. https://doi.org/10.18203/issn.2454-2156.IntJSciRep20161878

[13] Miltenburg, A.S., Roggeveen, Y., Shields, L., Elteren, M., van, Roosmalen, J., van, Stekelenburg, J. and Portela, A. (2015) Impact of Birth Preparedness and Complication Readiness Interventions on Birth with a Skilled Attendant: A Systematic Review. PLoS ONE, 10, e0143382. https://doi.org/10.1371/journal.pone.0143382

[14] Bagheri, A., Simbar, M., Samimi, M., Nahidi, F. and Majd, H.A. (2017) Exploring the Concept of Continuous Midwifery-Led Care and Its Dimensions in the Prenatal, Perinatal, and Postnatal Periods in Iran (Kashan). Midwifery, 51, 44-52. https://doi.org/10.1016/j.midw.2017.05.003

[15] Barimani, M. and Hylander, I. (2012) Joint Action between Child Health Care Nurses and Midwives Leads to Continuity of Care for Expectant and New Mothers. International Journal of Qualitative Studies on Health and Well-Being, 7, 18183. https://doi.org/10.3402/qhw.v7i0.18183

[16] Idemudia, E.S. and Fagbamigbe, A.F. (2015) Barriers to Antenatal Care Use in Nigeria: Evidences from Non-Users and Implications for Maternal Health Programming. BMC Pregnancy and Childbirth, 15, Article No. 95. https://doi.org/10.1186/s12884-015-0527-y

[17] Almalik, M.M. (2017) Understanding Maternal Postpartum Needs: A Descriptive Survey of Current Maternal Health Services. Journal of Clinical Nursing, 26, 46544663. https://doi.org/10.1111/jocn.13812

[18] Kaso, M. and Addisse, M. (2014) Birth Preparedness and Complication Readiness in Robe Woreda, Arsi Zone, Oromia Region, Central Ethiopia: A Cross-Sectional Study. Reproductive Health, 11, Article No. 55. https://doi.org/10.1186/1742-4755-11-55

[19] Ahluwalia, I.B., Robinson, D., Vallely, L., Gieseker, K.E. and Kabakama, A. (2010) Sustainability of Community-Capacity to Promote Safer Motherhood in Northwestern Tanzania: What Remains? Global Health Promotion, 17, 39-49. https://doi.org/10.1177/1757975909356627

[20] Odetola, T.D. (2015) Health Care Utilization among Rural Women of Child-Bearing Age: A Nigerian Experience. The Pan African Medical Journal, 20, 151. https://doi.org/10.11604/pamj.2015.20.151.5845

[21] Abiyot, T., Kassa, M., Buruh, G. and Kidanu, K. (2015) Awareness of Obstetric Danger Signs and Its Associated Factors among Pregnant Women in Public Health Institutions, Mekelle City, Tigray, Ethiopia 2014. Journal of Pregnancy \& Child Health, 2, 167. https://doi.org/10.4172/2376-127X.1000167

[22] Ekabua, J.E., Ekabua, K.J., Odusolu, P., Agan, T.U., Iklaki, C.U. and Etokidem, A.J. (2011) Awareness of Birth Preparedness and Complication Readiness in Southeastern Nigeria. ISRN Obstetrics and Gynecology, 2011, Article ID: 560641. https://doi.org/10.5402/2011/560641

[23] Morhason-Bello, I.O., Fagbamigbe, A.F., Mumuni, T.O., Adesina, O.A., Abdus-Salam, A.R., Ifemeje, A. and Ojengbede, O.A. (2016) Evaluation of Correct Knowledge of Key Danger Signs in Pregnancy among Antenatal Clinic Attendees at a Tertiary Health Facility in Nigeria. Nigerian Journal of Clinical Practice, 19, 227-232. https://doi.org/10.4103/1119-3077.164347

[24] Liang, J., Dai, L., Zhu, J., Li, X., Zeng, W., Wang, H., Li, Q., Li, M., Zhou, R. and Wang, Y. (2011) Preventable Maternal Mortality: Geographic/Rural-Urban Differences and Associated Factors from the Population-Based Maternal Mortality Surveillance System in China. BMC Public Health, 11, Article No. 243. https://doi.org/10.1186/1471-2458-11-243

[25] Pacagnella, R.C., Cecatti, J.G., Osis, M.J. and Souza, J.P. (2012) The Role of Delays 
in Severe Maternal Morbidity and Mortality: Expanding the Conceptual Framework. Reproductive Health Matters. An International Journal on Sexual and Reproductive Health and Rights, 20, 155-163. https://doi.org/10.1016/S0968-8080(12)39601-8

[26] Aquino, M.R.J.R.V., Olander, E.K., Needle, J.J. and Bryar, R.M. (2016) Midwives' and Health Visitors' Collaborative Relationships: A Systematic Review of Qualitative and Quantitative Studies. International Journal of Nursing Studies, 62, 193-206. https://doi.org/10.1016/j.ijnurstu.2016.08.002

[27] World Health Organization (2015) Standards for Maternal and Neonatal Care. Birth and Emergency Preparedness in Antenatal Care.

[28] WHO (2016) SDG 3: Ensure Healthy Lives and Promote Wellbeing for All at All Ages.

[29] Oluyemisi, A.F., Oyadiran, G.O., Ijedimma, M.O., Akinlabi, B.O. and Adewale, A.J. (2014) Perception of Pregnant Women towards Midwives: Attitude and Practice during Child Delivery in Health Institutions in Ogbomoso, South-West, Nigeria. Nigeria Epidemiology Biostatistics and Public Health, 11, 1-7.

[30] Owino, J. (2012) Owino's Theory: Nurse-Client Interaction for Childbirth Preparedness Analysis and Evaluation. Lambert Academic Publishers, Germany.

[31] Bintabara, D., Mohamed, M.A., Mghamba, J., Wasswa, P. and Mpembeni, R.N. (2015) Birth Preparedness and Complication Readiness among Recently Delivered Women in Chamwino District, Central Tanzania: A Cross Sectional Study. Reproductive Health, 12, 44. https://doi.org/10.1186/s12978-015-0041-8

[32] Newman, M.A. (2008) Transforming Presence: The Difference that Nursing Makes. F. A. Davis, Philadelphia, PA, 35.

[33] Macharia, K.S., Jelagat, R.R. and Juma, M.D. (2015) Applying Margaret Newman's Theory of Health as Expanding Consciousness to Psychosocial Nursing Care of HIV Infected Patients in Kenya. American Journal of Nursing Science, 4, 6-11.

https://www.researchgate.net/publication/267857087_Applying_Margaret_Newman s_theory_of_health_as_expanding_consciousness_to_psychosocial_nursing_care_o f_HIV_infected_patients_in_Kenya https://doi.org/10.11648/j.ajns.s.2015040201.12

[34] Dol, J., Kohi, T., Campbell-Yeo, M., Murphy, G.T., Aston, M. and Mselle, L. (2019) Exploring Maternal Postnatal Newborn Care Postnatal Discharge Education in Dar es Salaam, Tanzania: Barriers, Facilitators and Opportunities. Midwifery, 77, 137-143. https://doi.org/10.1016/j.midw.2019.07.009

[35] Freytsis, M., Phillippi, J.C., Cox, K.J., Romano, A. and Cragin, L. (2017) The American College of Nurse-Midwives Clarity in Collaboration Project: Describing Midwifery Care in Inter-Professional Collaborative Care Models. Journal of Midwifery \& Women's Health, 62, 101-108. https://doi.org/10.1111/jmwh.12521

[36] Owino, J., Legault, F., Mumbo, H.M., Odera, O. and Ayugi, M.E. (2013) A Grounded Theory Study for Antenatal Care. European Scientific Journal August Edition, 9, 229-238.

[37] Kabakyenga, J.K., Östergren, P.O., Turyakira, E. and Pettersson, K.O. (2012) Influence of Birth Preparedness, Decision-Making on Location of Birth and Assistance by Skilled Birth Attendants among Women in South-Western Uganda. PLoS ONE, 7, e35747. https://doi.org/10.1371/journal.pone.0035747

[38] Mei, J.Y., Afshar, Y., Gregory, K.D., Kilpatrick, S.J. and Esakoff, T.F. (2016) Birth Plans: What Matters for Birth Experience Satisfaction. Birth, 43, 144-150. https://doi.org/10.1111/birt.12226 
[39] da Gama, S.G.N., Viellas, E.F., Torres, J.A., Bastos, M.H., Brüggemann, O.M., Filha, M.M.T., do Carmo Leal, M., et al. (2016) Labor and Birth Care by Nurse with Midwifery Skills in Brazil. Reproductive Health, 13, 12.

https://doi.org/10.1186/s12978-016-0236-7 